\title{
Varia ORCA Congress 1973
}

The 20th ORCA Congress will take place 20-22 July 1973 in Zurich, Switzerland, in Hotel Nova Park. As previously announced (refer to Caries Res. 6: 377, 1972) the deadline for announcement of titles and submission of preliminary abstracts is 15th January 1973. For the preliminary abstract no special form or number of words is required, and they should be received before 15th January by Prof. K.G. König, Medical Faculty, University of Nijmegen, Nijmegen, The Netherlands.

Definite abstracts should be submitted on special abstract forms - before 1st June 1973 - to Dr. B. Guggenheim, P.O. Box 138, Cl1-8028 Zurich, Switzerland, unless an author has been notified (between 10th and 15th February) that his paper is not accepted for presentation.

Arrangements for accomodation will be offered in the form of 'Congress Packages' by DANZAS A.G., Zurich. Those on ORCA mailing lists will receive abstract forms, information and registration forms automatically in January. Additional information can be obtained from Dr. B. Guggenheim, on travel arrangements from a local DANZAS agency. 